\title{
Cultural Foundations of Transparent Governments
}

\section{Judith Reid}

\section{US Department of Defense}

\begin{abstract}
Defense Institution Building focuses on change management at the Ministry of Defense level. In order to make sustainable change in any government, the solution has to work through and with the culture of that society. There are ways to reduce hierarchy and uncertainty in national strategy development, national defense organization, legal constructs, human resource management, financial management, and educational processes. Cultures change from within. If advisors understand the cultural foundations at work, they can better help countries chart paths toward sustainable, transparent governance.
\end{abstract}

Keywords: Defense Institution Building, defense reform, intellectual interoperability, culture, Hofstede.

\section{Introduction}

Governments are reflections of the people they serve. Each society has its own culture, its own set of subconscious rules that facilitate communication, determine acceptable behavior, and guide the community's interactions. In order to maximize success, the U.S. Department of Defense's (DoD) program to facilitate improved Defense Institution Building (DIB) in other states needs to work within the cultural foundations of the partner nations it engages in defense reform.

A common cultural profile in countries ruled by dictators includes very high power distance models and very high uncertainty avoidance. These are two of Geert Hofstede's cultural structures explained in Culture's Consequences: Inter- 
national Differences in Work-Related Values. ${ }^{1}$ This cultural model is found in many countries with authoritarian governments.

Hofstede created a way to compare the cultural structure of human groups. His first marker was a scale of hierarchy in society. If a society has rigid caste systems with numerous layers, then it has a high Power Distance Indicator (PDI). Movement between hierarchical layers is difficult, and there is almost total separation between the elite and those at the bottom of the pecking order. Centralized management, rigid inequality, and formal rules and approvals from non-ending chains of superiors are all hallmarks of high PDI. Subordinate and superior relationships are based on emotion. While this behavior is mandated from on top, what keeps it locked in place are the perceptions of the people at the lower end of the hierarchy that this is just the way things are. Their acceptance of their low status is what keeps the PDI in place and thriving, not the insistence on inequality from the top of the chain. Hierarchies can be tall and rigid or have only a few impermeable layers. According to Culture's Consequences, numerous closed societies have a high PDI quotient. ${ }^{2}$

Uncertainty Avoidance (UAI) is observed when members of a society would do almost anything to keep the status quo. The risk of the unknown is too frightful to ponder in these populations. These groups love structure, have lots of specific laws and rules, trust experts and technical solutions, and disdain uncertainty. Top managers do not focus on strategy, but rather on operations. Education is highly structured learning with clear right and wrong answers. Life may be unfair or even brutal, but in high UAI countries, understanding the rules and expected behavior are worth more than any potential gain from rocking the boat. This is one of the key reasons that change is so difficult to institute in some of the countries that need it the most. Many nations with autocratic rulers have high UAl quotients, according to Hofstede. ${ }^{3}$

There are two more pillars of Hofstede's original work that have a lesser role in creating despotic governments: Individualism (IND) and Masculinity (MASC) Indices. In the Individualism Index, societies are gauged on a scale of individualism versus collectivism. Is there a sense of "being in this together" as a group, or is it "every man for himself?" In collective societies, relationships are more important than tasks, opinions are predetermined by group membership, and one's private life is not as important as the group's needs. Bosses and employees are more familial, and harmony and consensus are the ultimate goals. ${ }^{4}$ A piece of this construct is the identification of the primary group. Does

1 Geert Hofstede, Culture's Consequences: International Differences in Work-Related Values (Newbury Park, CA: Sage, 1980).

2 Geert Hofstede, Gert Jan Hofstede, and Michael Minkov, Cultures and Organizations: Software of the Mind, Intercultural Cooperation and Its Importance for Survival, 3rd ed. (New York: McGraw-Hill, 2010), 76.

3 Hofstede, Culture's Consequences, 203-217.

4 Hofstede, Culture's Consequences, 124-130. 
society concern itself mostly with its individuals or nuclear families (high IND), or the extended family, clan, or township, as seen in more collective societies (low IND)? Many non-democratic nations register as collective societies (low IND) on Hofstede's model. ${ }^{5}$

According to Hofstede's model, highly masculine societies are more competitive than cooperative; have strong rules; recognition and advancement are important; failing is considered disastrous; and management is decisive and aggressive. A more feminine society would be collaborative, nurturing, and focused on quality of life. Management in more feminine societies is by intuition and consensus and conflict is resolved by compromise and negotiation. ${ }^{6}$

The combination of high power distance and high uncertainty avoidance creates the cultural conditions for dictatorships to thrive. ${ }^{7}$ Super strong hierarchies enforced by intimidation are paired with populations that fear the unknown (even if the status quo is dreadful). This combination of high PDI and high UAI results in societies bound by rule books, an inability to make decisions except at the highest level of an organization, fear-based group-think, and strong compartmentalization of ideas, organizations and goods. These behaviors result in opaque business processes and cultures of secrecy, and they are ripe for graft. In this sort of environment, without a strong desire to change among the people and long-term intervention from others, the face may change, but the dictator will remain.

\section{Defense Institution Building}

The Defense Institution Building (DIB) program of the U.S. Department of Defense (DoD), much like the rest of Defense Reform (DR), works to create transparent, democratic governance and institutions that support the rule of law and provide services to citizens. The program focuses in part on defense strategy; national defense organization; legal institutions; human and financial resource management; and educational processes. ${ }^{8}$

By its very presence, DIB constitutes change management. As a program, it is never forced upon another country. Rather the type and level of consultation a country might receive is negotiated through the U.S. Embassy, U.S. Department of Defense, and the designated Combatant Command. Receiving Ministries of Defense request help with everything from creating an NCO Corps to facilitating strategy development. Because governance is a reflection of the society it serves, any lasting change in governing processes must reach down into the country's cultural foundation to survive.

5 Hofstede, Cultures and Organizations, 89-134.

6 Hofstede, Cultures and Organizations, 135-186.

7 Hofstede, Cultures and Organizations, 412-416.

8 Office of the Under Secretary of Defense for Policy, "DoD Directive 5205.82 Defense Institution Building (DIB)," January 27, 2016. 
From a cultural perspective, in order to unlock a frozen high PDI and high UAI environment, a society must begin moving from a state of fear toward openness. ${ }^{9}$ To unlock this dictatorial paradigm, work with the host nation must increase its society's overall sense of trust. One place to begin would be to improve the rule of law so the public begins to feel a sense of fairness. Prosecute corruption, since it feeds uncertainty avoidance. Improve critical thinking in the population, not just rote memorization. Help students learn to question the theory, the teacher, the authority. All of these actions help reduce fear and flatten out overly strong hierarchies.

Below are six common functions of DIB and the cultural direction necessary to move a society from one that craves a dictator to one that can support transparent governance. These functions include defense strategy; national defense organization; legal institutions; human resource management; financial management; and education.

\section{Strategy}

One of the key tenets of open, liberal democracy is a national security strategy wrapped around concepts of economic growth, self-preservation, and world alliances. A national security strategy addresses issues of concern to a nation's self-preservation: real and perceived enemies, control of the external environment, and sovereignty.

Having a national security strategy (NSS) that is open and made public can invite criticism and scrutiny to the country's political leaders. Under normal circumstances, those are ideas that should direct the subordinate strategies that lead to action. A country's national military strategy (NMS) should derive from the national security strategy. The NMS focuses priorities for the country's military assets. If part of one country's NSS is to protect its people, then part of its NMS could be consequence management. That could lead to the military being prepared to respond to natural and man-made disasters. Since the military is often one of the most organized and deployable entities in any federal government, disaster response is a common mission of many countries' military land forces.

In a dictatorial government, there is often no public NMS, much less an open NSS. The overarching direction of the security apparatus and military focus are kept close, remain opaque, and are designed to keep the power brokers in place. Only the inner circle of generals knows some of the NMS. The rank and file do as they are told in a classic strong hierarchical framework. This leads to an organizational culture of secrecy reinforced through blind hierarchical obedience (PDI), coupled with the desire to keep the difficult status quo over the more grave fear of the unknown (UAI).

9 Richard Barrett, Love, Fear and the Destiny of Nations: The Impact of the Evolution of Human Consciousness on World Affairs, vol. 1 (Bath, UK: Fulfilling Books, 2012), 217227. 


\section{National Defense Organization}

In order to protect secrecy and encourage blind obedience, countries with strong dictatorial governments create a small inner circle of trust surrounded by heavy bureaucracies with layer upon layer of redundant functions. Organizations are stove-piped and insulated from one another. A strong inner and outer group orientation is encouraged, with the inner circle excluding the greater organization, which makes the general organization mistrust other departments. Uncertainty is avoided at all costs. The rank and file know that there will be no surprises and that even simple decisions will be forwarded to the leadership. This creates governmental ministries that cannot and will not communicate with each other and that fail to serve the public.

\section{Legal Institutions}

The rule of law is key to shifting control from a strong man to common citizens. Open, democratic governments are structured with checks and balances among the executive, legislative, and judicial functions so that no one function can wrest control from the others. This system is not perfect in any country, but the continuance to strive toward transparency and fairness empowers standards of conduct, codes of military justice, ethical guidelines, and even whistle-blowing. The more these guidons of fairness prevail, the more trust society can grant to its government.

\section{Human Resources Management}

Dictatorial governments create human resource processes that divide and conquer. They are the opposite of a merit system. People are promoted based on name or affiliation, not on their abilities or what assets they may bring to the job. Those in power are protected by filling in the ranks with like-minded underlings whose most important asset is loyalty to the power brokers. Often, those on top are highly competitive, while the masses see themselves as one collective whole. The HR domain is where UAI can be structurally increased, since promoting only those loyal to the power brokers protects the power imbalance.

\section{Financial Management}

If the national security strategy is opaque, then the financial system could be compared to an underground maze of tunnels with only one map. Aided by its obscure nature, the financial system is designed to benefit the elite. Power and money are kept centrally controlled; the organization is divided into the "in" and "out" groups; the leadership is highly competitive while the masses react collectively; and any hint of uncertainty wreaks havoc on everyone. In these societies, even those at the bottom of the ladder prefer brutal treatment to the uncertainty of going after any other option. Since the people on the bottom of the pyramid continue to recognize the higher stature of the power brokers and 
perpetuate these strong hierarchies, they recognize and accept that the financial system is rigged against them and that it offers no fairness in financial matters. Bribes large and small become the norm as underpaid bureaucrats are forced to supplement their income, while the power brokers are rewarded by financial trickery.

\section{Education}

Good education broadens the mind and creates new neural pathways that can connect in innovative ways with other established disciplines. Training is skill development - teaching or improving a concrete skill set. In dictatorial environments, there is little true education within the defense department. Beyond the individual and advanced technical training, there are few opportunities to engage adult learning institutions. Teaching institutions simply indoctrinate the students.

\section{Recognizing there is a Problem}

Loyalty is an outgrowth of strong hierarchy mixed with strong uncertainty avoidance. When a group requires loyalty of its members as part of a whole mix of values, such as the US Army values of loyalty, duty, respect, selfless service, honor, integrity, and personal courage, then it is balanced. When loyalty is by far the most important characteristic required of members of the group, then the extremely high level of uncertainty avoidance of the body is evidenced. Add a strong hierarchy, and the result is a closed fraternity, a gang, a dictatorship.

On the "love-fear continuum," ${ }^{10}$ the insistence on loyalty above all else is an outgrowth of fear. This fear manifests in strong hierarchies that keep people in their places, along with a fear of the unknown. Strong control by the power brokers is perceived as the cure to this two-headed fear. The greater the fear within the leadership and the people, the stronger the hierarchy and desire for absolute control by all levels of the society.

\section{Unlocking the Paradigm}

How does this environment of fear shift in the other direction toward care, toward openness, toward collaboration? First, fear has to be neutralized. Rule of law is a key lever in reducing corruption, lightening gray economies, and easing dictatorial strangleholds. When communities on the bottom of the hierarchy see that there can be legal justice meted out to those who would rule with impunity, then the rigidness of the hierarchy begins to soften.

Second, care must be infused. People at the bottom of society already largely understand cooperation since they have learned to lean on each other to survive. The seed is there and can grow from the roots to the stem and to

10 Barrett, Love, Fear, and the Destiny of Nations, 113-133. 
the leaves as long as trust can start to flourish in the cultural environment. If the outlaws of society can be brought to justice, then societal trust can take root and grow.

This may be accelerated by making amends. In post-Apartheid South Africa, the Truth and Reconciliation Councils were designed to bring evil out into the open, make amends for it, ask forgiveness, and promise a change in future behavior. It was public, a bit brutal, and necessary for the Mandela era to take root. ${ }^{11}$ Is South Africa today a paradise of peace and love? It is moving in that direction - a direction of self-determination, expanding cultural identity, and collaborative governance.

A key shift in culture usually requires some sort of crisis to break the mold of fear and derisiveness. Change agents can include war, terrorist attack, famine, or even a decision to transform if the pain becomes unbearable. Some foresighted leaders have paved the way from highly competitive environments toward collaborative ones. Mikhail Gorbachev and his glasnost movement led to the dissolution of the Soviet Union. President FW de Klerk of South Africa eradicated Apartheid and led South Africa toward inclusionary politics. Numerous dictatorships in Latin America converted from totalitarian regimes to fledgling democracies in the 1990s.

This does not mean that any of these countries are bastions of fairness and peace today, but they are moving away from fear / secrecy / competitiveness toward care/openness/cooperation. As these societies move toward openness and collaboration, societal trust gets ever stronger, the rule of law becomes the expectation, and the ability of an autocrat to take root subsides.

\section{DIB Strategy to Increase Transparency}

Let us return to Hofstede's model and see how it can inform the DIB process. In order to reduce the cultural dimension that fosters dictatorial rule, NSS and NMS need to shift from opaque to transparent. They should no longer exist just for a leader's protection and control, but rather should focus on the country's security and military needs as a whole. The NSS and NMS should move toward collective and collaborative policies, and be open to transparent governance based on collective values rather than based on fear of the unknown with its concomitant need for control. In more openly democratic governance, strategies can be developed beyond the year of execution, looking three, five, or even ten years ahead.

\section{National Defense Organizations that Increase Transparency}

In an open society, national defense organizations are different from those in a dictatorial government. In an open society, the organizational structure is transparent. There may still be tall hierarchies in place, but the need for abso-

11 Steve York, director, Confronting the Truth, filmed for the United States Institute for Peace in 2004. 
lute control is missing. Leadership roles in the organization are based on merit, not on some crazy puzzle of loyalty and patronage. In a healthy government, decisions are decentralized, and redundant organizations are eliminated.

\section{Legal Constructs that Increase Transparency}

The execution of rule of law is key to building citizen trust, reducing UAI and PDI. In a healthy government, there are Inspectors General, ethics committees, and whistle-blower protections. There are police departments that protect the peace, courts that rule fairly, and prisons that are humane. There is a sense of fairness for the general population, not a skewed balance that favors only the leadership. In an open government, corruption and graft are prosecuted.

\section{Human Resources Management that Increase Transparency}

Personnel systems are reflections of an organization's strategies. Are they designed to keep the powerful on top? Are promotions based upon loyalty to the leader, or do they benefit the organization's mission? To move away from fear, HR systems need to be based on merit and the benefit each person can bring to the organization. In some rigid hierarchies, position is based upon affiliation not performance. This includes countries with established aristocracies, and it filters down into many high PDI societies. In a healthy organization, the rank and file feel confident that they can bring most HR issues to their leadership and the HR department without retribution. Promotions and discipline are based on merit.

\section{Financial Management to Increase Transparency}

Part of this overall sense of fairness is to pay government workers a living salary. When wages are insufficient to live, when bonuses are based on loyalty, or when the rank and file have to rely on "transaction fees" to survive, then fear pervades and strong men rule. When families believe they have enough income to take care of their needs, then a cooperative spirit can ease into the competitive environment.

A financial system based on openness and collaboration also includes funding for social services such as basic health care, hospitals, and care for the indigent. Financial systems of governments that want to help society also include funds for infrastructure like roads, waterways, and transportation systems. All of these things lead toward economic growth and prosperity.

Because the financial systems mirror and fund the governmental system, in an open system of governance, there are also checks and balances on the books. There are systems of fair auditing, oversight of leaders with contracting authority, and mechanisms in place to report fraud waste and abuse of power and funds. All of these programs reduce uncertainty and aid the cultural shift toward democratic governance. 


\section{Education to Increase Transparency}

Many believe that "knowledge is power." In a dictatorial government, knowledge is closely guarded. Critical information is kept centralized, and critical thinking is kept underground. Education is given only to the most loyal, and limited training is given to the masses. In a society with high Uncertainty Avoidance, students long for clear answers. There is a clearly accepted right answer, and every other is considered wrong. In fact, this black/white viewpoint is a microcosm of the greater society, where the line between right and wrong is clearly delineated and enforced. In Post-Soviet satellite countries, education in many defense colleges consisted of a lecturer reading four hours of content to a large group of students. Some might call this indoctrination, not education. Open, accessible education that nurtures critical thinking is a key component of open societies.

\section{Conclusion}

A population ensconced in dictatorial leadership will accept its place on the bottom of the hierarchy, the lack of open strategies or organizational structures, and the abuse of patronage just to keep uncertainty at bay. This society will accept that loyalty is the only important value, that resources are shared based on fidelity, and that advancement is only for the "in" group.

If DIB Programs are to take hold, then UAI must be reduced through enforced rule of law, living wages, and merit promotions. When rigid laws relax to become administrative policies that guide, then PDI softens and absolute control eases. Decreases in both UAI and PDI make up the key groundwork needed to reduce dictatorial chokeholds on societies.

In order to make a fundamental change in any government, the solution has to work through and with the culture of that society. Cultures change from within. If advisors understand the cultural foundations at work, they can better help countries chart paths toward sustainable, transparent governance.

\section{Disclaimer}

The opinions expressed in this article are those of the author and do not reflect the policy of the U.S., German, or any other government.

\section{About the author}

Judith Reid works for the U.S. Department of Defense in security cooperation. She led the Defense Institution Building Program at US European Command from 2011-2015. Her doctorate focused on the relationship between cultural understanding and military mission success.E-mail: DrJudithReid@gmail.com. 